\title{
Recurrent Circuits in Layer II of Medial Entorhinal Cortex in a Model of Temporal Lobe Epilepsy
}

\author{
Sanjay S. Kumar, ${ }^{1 *}$ Xiaoming Jin, ${ }^{2 \star}$ Paul S. Buckmaster, ${ }^{1,2}$ and John R. Huguenard ${ }^{2}$ \\ Departments of ${ }^{1}$ Comparative Medicine and ${ }^{2}$ Neurology and Neurological Sciences, Stanford University, Stanford, California 94305
}

\begin{abstract}
Patients and laboratory animal models of temporal lobe epilepsy display loss of layer III pyramidal neurons in medial entorhinal cortex and hyperexcitability and hypersynchrony of less vulnerable layer II stellate cells. We sought to test the hypothesis that loss of layer III pyramidal neurons triggers synaptic reorganization and formation of recurrent, excitatory synapses among layer II stellate cells in epileptic pilocarpine-treated rats. Laser-scanning photo-uncaging of glutamate focally activated neurons in layer II while excitatory synaptic responses were recorded in stellate cells. Photostimulation revealed previously unidentified, functional, recurrent, excitatory synapses between layer II stellate cells in control animals. Contrary to the hypothesis, however, control and epileptic rats displayed similar levels of recurrent excitation. Recently, hyperexcitability of layer II stellate cells has been attributed, at least in part, to loss of GABAergic interneurons and inhibitory synaptic input. To evaluate recurrent inhibitory circuits in layer II, we focally photostimulated interneurons while recording inhibitory synaptic responses in stellate cells. IPSCs were evoked more than five times more frequently in slices from control versus epileptic animals. These findings suggest that in this model of temporal lobe epilepsy, reduced recurrent inhibition contributes to layer II stellate cell hyperexcitability and hypersynchrony, but increased recurrent excitation does not.
\end{abstract}

Key words: temporal lobe epilepsy; entorhinal cortex; glutamate photo-uncaging; recurrent excitation; recurrent inhibition; stellate cell

\section{Introduction}

Temporal lobe epilepsy is the most common type of epilepsy in adults (Engel et al., 1997), and clinical evidence suggests that entorhinal cortex is involved. Spontaneous seizures have been recorded in the entorhinal cortex of patients with temporal lobe epilepsy (Spencer and Spencer, 1994; Bartolomei et al., 2005). Stimulation of the entorhinal cortex evokes responses in the hippocampus that resemble spontaneous interictal spikes (Rutecki et al., 1989; Wilson et al., 1990). Magnetic resonance imaging studies show that the entorhinal cortex is smaller in patients with temporal lobe epilepsy (Bernasconi et al., 1999; Jutila et al., 2001), and patients display preferential loss of layer III neurons in the medial entorhinal cortex (Du et al., 1993; Yilmazer-Hanke et al., 2000) (but see Dawodu and Thom, 2005). Similar patterns of neuron loss occur in laboratory animal models of temporal lobe epilepsy (Schwob et al., 1980; Clifford et al., 1987; Du et al., 1995; Ribak et al., 1998). These findings suggest that the medial entorhinal cortex may contribute to initiation of seizure activity and its propagation into the hippocampus. One potential route is from surviving layer III neurons via the temporoammonic pathway (Wozny et al., 2005; Ang et al., 2006). Another possibility is the perforant path, which consists of axon projections from layer II stellate cells.

\footnotetext{
Received July 25, 2006; revised Nov. 22, 2006; accepted Dec. 21, 2006.

This work was supported by National Institutes of Health-National Institute of Neurological Disorders and Stroke.

*S.S.K. and X.J. contributed equally to this work.

Correspondence should be addressed to Paul Buckmaster, Department of Comparative Medicine, Stanford University, R321 Edwards Building, 300 Pasteur Drive, Stanford, CA 94305-5342. E-mail: psb@stanford.edu.

DOI:10.1523/JNEUROSCI.3182-06.2007

Copyright $\odot 2007$ Society for Neuroscience $\quad$ 0270-6474/07/271239-08\$15.00/0
}

Layer II stellate cells in the entorhinal cortex are the major source of excitatory, synaptic input to the dentate gyrus (Segal and Landis, 1974; Steward and Scoville, 1976). In animal models of temporal lobe epilepsy, stellate cells display prolonged excitatory synaptic responses when stimulated (Bear et al., 1996; Scharfman et al., 1998; Tolner et al., 2005) and generate excessive, spontaneous, hypersynchronous input to dentate granule cells (Buckmaster and Dudek, 1997; Kobayashi et al., 2003). Hyperexcitability of layer II stellate cells in epileptic pilocarpine-treated rats has been attributed, at least in part, to loss of GABAergic synaptic input (Kumar and Buckmaster, 2006).

Synaptic reorganization is another potential mechanism of hyperexcitability of layer II stellate cells. Many types of neurons display aberrant axon sprouting and synaptogenesis in epilepsy models (Nadler et al., 1980; Salin et al., 1995; Perez et al., 1996; McKinney et al., 1997), raising the possibility of recurrent excitatory synapses in the entorhinal cortex in patients and models of temporal lobe epilepsy. Analogous to loss of hilar neurons and sprouting of granule cell axons in the dentate gyrus (Nadler et al., 1980), loss of layer III neurons in the medial entorhinal cortex, which normally projects axons superficially (Köhler, 1986) and synapses with dendritic spines (Germroth et al., 1991), might trigger or permit development of aberrant recurrent excitatory synapses among layer II stellate cells. In control animals, layer II stellate cells project axon collaterals to layers I and II (Lingenhöhl and Finch, 1991; Buckmaster et al., 2004) where they might synapse with and excite neighboring stellate cells (Biella et al., 2002). Simultaneous recordings from pairs of layer II stellate cells in control rats, however, did not reveal recurrent excitatory synapses (Dhillon and Jones, 2000).

To evaluate recurrent excitatory and inhibitory circuits in the 
medial entorhinal cortex of epileptic pilocarpine-treated rats, we used laser-scanning photo-uncaging of glutamate to focally stimulate neurons in layer II while recording responses in stellate cells. We asked whether functional recurrent excitatory circuits are normally present in control rats and whether epileptic rats display enhanced recurrent excitation (see Fig. $1 A$ ). Spontaneous inhibitory synaptic input to layer II stellate cells is reduced in epileptic rats (Kumar and Buckmaster, 2006); however, evoked inhibitory synaptic potentials are reported to be normal (Bear et al., 1996). To address this issue, we evaluated photostimulationevoked inhibitory responses of stellate cells in control and epileptic rats.

\section{Materials and Methods}

Animals. All experiments were performed in accordance with National Institutes of Health Guide for the Care and Use of Laboratory Animals and were approved by the Stanford University Institutional Animal Care and Use Committee. Male Sprague Dawley rats (41-42 d of age) were treated with pilocarpine as described previously (Buckmaster, 2004). Briefly, pilocarpine was administered $(380 \mathrm{mg} / \mathrm{kg}$, i.p.) $20 \mathrm{~min}$ after atropine methylbromide ( $5 \mathrm{mg} / \mathrm{kg}$, i.p.). Diazepam ( $10 \mathrm{mg} / \mathrm{kg}$, i.p.) was administered $2 \mathrm{~h}$ after the onset of status epilepticus and repeated as needed. Beginning 1 week after pilocarpine treatment, rats were video-monitored (40 h/week) for spontaneous motor seizures. Epileptic rats $(n=6)$ were used for slice experiments 19-81 d after pilocarpine treatment by which time at least two spontaneous seizures had been observed. Control rats $(n=7)$ were treated identically but did not experience status epilepticus and were never observed to have spontaneous seizures. The age at the time of slice experiment was similar in control and epileptic groups ( $82 \pm$ 12 and $93 \pm 10 \mathrm{~d}$, respectively; $p>0.5$ ).

Slice preparation and electrophysiology. Rats were deeply anesthetized with urethane $(1.5 \mathrm{~g} / \mathrm{kg}$, i.p.) and decapitated, and horizontal slices (350 $\mu \mathrm{m}$ ) were prepared with a microslicer (VT1000S; Leica, Nussloch, Germany) in a chilled $\left(4^{\circ} \mathrm{C}\right)$ low- $\mathrm{Ca}^{2+}$, low- $\mathrm{Na}^{+}$solution containing the following (in $\mathrm{mm}$ ): 230 sucrose, $10 \mathrm{D}$-glucose, $26 \mathrm{NaHCO}_{3}, 2.5 \mathrm{KCl}, 1.25$ $\mathrm{NaH}_{2} \mathrm{PO}_{4}, 10 \mathrm{MgSO}_{4}$, and $0.5 \mathrm{CaCl}_{2}$ equilibrated with a $95 \%$ and $5 \%$ mixture of $\mathrm{O}_{2}$ and $\mathrm{CO}_{2}$. Slices were allowed to equilibrate in oxygenated artificial CSF (aCSF) (in mM: $126 \mathrm{NaCl}, 26 \mathrm{NaHCO}_{3}, 3 \mathrm{KCl}, 1.25$ $\mathrm{NaH}_{2} \mathrm{PO}_{4}, 2 \mathrm{MgSO}_{4}, 2 \mathrm{CaCl}_{2}$, and 10 D-glucose, $\mathrm{pH} 7.4$ ) first at $32^{\circ} \mathrm{C}$ for $1 \mathrm{~h}$ and subsequently at room temperature before being transferred to the recording chamber. Typical recordings lasted 25-30 min per slice and approximately five cells were recorded from each animal.

Recording electrodes were pulled from borosilicate glass tubing (1.5 $\mathrm{mm}$ outer diameter) and had impedances of 4-7 $\mathrm{M} \Omega$ when filled with internal solution for voltage-clamp recordings, which contained the following (in mM): 130 Cs-gluconate, $5 \mathrm{CsCl}, 11 \mathrm{EGTA}, 1 \mathrm{CaCl}_{2}, 2 \mathrm{MgCl}_{2}$, 10 HEPES, $2 \mathrm{Na}_{2} \mathrm{ATP}, 0.5 \mathrm{NaGTP}$, and $0.5 \%$ biocytin. Inclusion of $11 \mathrm{~mm}$ EGTA in the recording pipette blocks depolarization-induced suppression of inhibition (Lenz and Alger, 1999). Therefore, it is unlikely that IPSCs recorded at $0 \mathrm{mV}$ holding potential were biased toward cannabinoid-insensitive events. For current-clamp recordings, internal solution contained the following (in $\mathrm{mm}$ ): $95 \mathrm{~K}$-gluconate, $40 \mathrm{KCl}, 5$ EGTA, $0.2 \mathrm{CaCl}_{2}, 10 \mathrm{HEPES}$, and $0.5 \%$ biocytin. Osmolarity of internal solutions was adjusted to $285-295 \mathrm{mOsm}$ and $\mathrm{pH}$ to 7.3 with $1 \mathrm{M} \mathrm{KOH}$ or $\mathrm{CsOH}$. Slices were transferred to a recording chamber where they were minimally submerged in high divalent cation aCSF (oxygenated in 95\% $\mathrm{O}_{2}$ and $5 \% \mathrm{CO}_{2}$ ) containing the following (in $\mathrm{mm}$ ): $121 \mathrm{NaCl}, 2.5 \mathrm{KCl}$, $1.25 \mathrm{NaH}_{2} \mathrm{PO}_{4}, 4 \mathrm{CaCl}_{2}, 4 \mathrm{MgSO}_{4}, 26 \mathrm{NaHCO}_{3}$, and 10 glucose. High concentrations of divalent cations were used to prevent polysynaptic recurrent excitation (Prince and Tseng, 1993; Lynch and Sutula, 2000; Shepherd et al., 2003), and $10 \mu \mathrm{M} 2$-amino-5-phosphonovaleric acid was added to block NMDA receptor-dependent events (Jin et al., 2006), including those generated by glutamate release from glia (Angulo et al., 2004; Fellin et al., 2004).

Recordings were obtained at room temperature $\left(22-23^{\circ} \mathrm{C}\right)$ from visually identified layer II stellate cells in medial entorhinal cortex under Nomarski optics with a $63 \times$ water-immersion lens and infrared video microscopy (Zeiss Axioskop; Zeiss, Oberkochen, Germany). Recordings
Table 1. Layer II stellate cell spontaneous postsynaptic currents and synaptic responses to focal photo-uncaging of glutamate in layer II medial entorhinal cortex of control and epileptic rats

\begin{tabular}{lcc}
\hline & Control & Epileptic \\
\hline EPSCs & & \\
$n$ (cells) & 26 & 30 \\
Spontaneous amplitude (pA) & $8.3 \pm 0.8$ & $9.5 \pm 0.6$ \\
Spontaneous frequency (Hz) & $3.6 \pm 0.6$ & $3.9 \pm 0.7$ \\
Number of sites stimulated per cell & $85 \pm 4$ & $88 \pm 5$ \\
Percentage of responding sites & $19 \pm 2$ & $19 \pm 3$ \\
Mean individual amplitude (pA) & $15 \pm 1$ & $14 \pm 2$ \\
Half-width (ms) & $6.1 \pm 0.2$ & $6.0 \pm 0.2$ \\
IPSCs & 15 & \\
$n$ (cells) & $30 \pm 3$ & 19 \\
Spontaneous amplitude (pA) & $0.10 \pm 0.02$ & $28 \pm 2$ \\
Spontaneous frequency (Hz) & $88 \pm 5$ & $0.10 \pm 0.04$ \\
Number of sites stimulated per cell & $14 \pm 4$ & $90 \pm 6$ \\
Percentage of responding sites & $98 \pm 14$ & $2 \pm 1^{* *}$ \\
Mean individual amplitude (pA) & $15.8 \pm 0.2$ & $62 \pm 15$ \\
Half-width (ms) & $\mathrm{n} / \mathrm{d}$ \\
\hline
\end{tabular}

Values represent mean $\pm \mathrm{SEM}{ }^{* *} p<0.005, t$ test. $\mathrm{n} / \mathrm{d}$, Not determined, because the number of events was insufficient for reliable analysis.

were obtained with an Axopatch 200A amplifier and pClamp software (Molecular Devices, Union City, CA), filtered at $2 \mathrm{kHz}$ (10 kHz for current clamp), digitized at $10-20 \mathrm{kHz}$, and stored digitally. Series resistance was monitored continuously, and those cells in which this parameter changed by $>30 \%$ were rejected. Access resistance was similar in control and epileptic groups ( $24 \pm 2$ and $24 \pm 2 \mathrm{M} \Omega$, control and epileptic; $n=$ 26 and 30 , respectively; $p>0.7, t$ test). Spontaneous and evoked postsynaptic current (PSC) data were analyzed using Mini Analysis (Synaptosoft, Decatur, GA). Threshold for event detection was set at three times root mean square noise level. Average root mean square noise levels were similar in control and epileptic groups $(1.4 \pm 0.1,1.4 \pm 0.1 \mathrm{pA} ; p=0.9$, $t$ test). Software-detected events were visually verified, and their frequency and amplitude were measured. These parameters could be measured accurately despite the presence of overlapping events. EPSC recordings were obtained at a holding potential of $-70 \mathrm{mV}$ and IPSC recordings at $0 \mathrm{mV}$. EPSCs were recorded without pharmacologically blocking $\mathrm{GABA}_{\mathrm{A}}$ receptor-mediated events to facilitate obtaining both EPSC and IPSC data from each recorded stellate cell. The chloride equilibrium potential calculated using the Nernst equation was $-64 \mathrm{mV}$, and thus driving force for IPSCs was negligible at the holding potential used for EPSC recordings. Average widths at half-maximum amplitude for evoked EPSCs $(6.1 \pm 0.2 \mathrm{~ms})$ were smaller than those for evoked IPSCs $(15.8 \pm 0.2 \mathrm{~ms} ; p<0.0001, t$ test $)$ (Table 1$)$, suggesting distinct populations of responses and minimal contamination between the two types of events. Before collecting photostimulus-evoked responses, spontaneous activity was recorded for at least $1 \mathrm{~min}$.

Photolysis of caged glutamate. Glutamate uncaging was performed as described previously (Deleuze and Huguenard, 2006; Jin el. al., 2006). Briefly, a frequency-tripled Nd:YVO $\mathrm{YV}_{4}$ laser (Series 3500 pulsed laser, 100 $\mathrm{kHz}$ repetition rate; DPSS Lasers, San Jose, CA) was interfaced with an upright microscope through its epifluorescence port via several mirrors and lenses. Movement of the laser beam was controlled precisely with mirror galvanometers (model 6210; Cambridge Technology, Cambridge, MA), and it was triggered by scanning and data acquisition software (developed by J. R. Huguenard, Stanford University, Stanford, CA), which also registered recorded soma position with respect to stimulation sites. Caged glutamate (methyl 1-[5-(4-amino-4-carboxybutanoyl)]-7nitroindoline-5-acetate; Sigma, St. Louis, MO) $(100 \mu \mathrm{M})$ was added to 20 $\mathrm{ml}$ of recirculating high divalent cation aCSF at the beginning of each experiment. Focal photolysis of caged glutamate was accomplished by switching the UV laser to give a $400-800 \mu$ s light stimulus through a $5 \times$ objective. To activate neurons in layer II of medial entorhinal cortex, a horizontally oriented grid $600-1200 \mu \mathrm{m}$ along the mediolateral axis and $180-240 \mu \mathrm{m}$ along the pial-white matter axis was used. Spacing between adjacent rows and columns of the grid was set to $50 \mu \mathrm{m}$, yielding grids 
with four to five rows and 13-24 columns. A pseudorandom stimulus sequence pattern with $1 \mathrm{~s}$ interstimulus interval was used. Repeated photo-uncaging at a given site evoked similar responses in recorded cells, and repeated photostimulation of the same region resulted in similar maps of synaptic input (supplemental Fig. $1 B-D$, available at www.jneurosci.org as supplemental material).

Data analysis. Photo-uncaging of glutamate can evoke direct responses, synaptic responses, or combinations of both (see Fig. $1 B$ ). Direct responses recorded in voltage-clamp mode peaked within $10 \mathrm{~ms}$ of photostimulation. However, current-clamp recordings revealed action potentials evoked as late as $100 \mathrm{~ms}$ after photostimulation (supplemental Fig. 1a, available at www.jneurosci.org as supplemental material), although most $(\sim 80 \%)$ occurred within the first $10-30 \mathrm{~ms}$. A measurement window of $100 \mathrm{~ms}$ duration (10-110 ms after photostimulation) was used for IPSCs, because the frequency of spontaneous IPSCs was quite low (Table 1); therefore, the relatively long measurement window would capture responses generated by late action potentials with minimal risk of including spontaneous events. The frequency of spontaneous EPSCs, in contrast, was higher (Table 1), and a shorter (20 ms) measurement window (10-30 ms after photostimulation) was used to reduce the effects of spontaneous events.

We evaluated several parameters to quantify characteristics of synaptic connectivity (Deleuze and Huguenard, 2006; Jin et al., 2006). Photostimulation sites were identified as responding if at least one postsynaptic current was detected within the measurement window. Percentages of responding sites were computed and plotted with respect to the mediolateral axis by averaging values for each column of stimulus sites. Composite amplitude was defined as the sum of peak amplitudes of all detected synaptic events during the measurement window. To evaluate the strength and mediolateral distribution of PSCs, the sum of all composite amplitudes within a given column of stimulus sites along the mediolateral axis was divided by the total number of stimulus sites within the column. The number of PSCs that occurred during the measurement window at each stimulus site was recorded. Mean individual PSC amplitude was obtained by dividing composite amplitude by the number of PSCs.

The probability of spontaneous IPSCs occurring during a measurement window is low (Table 1) because of their low frequency in high divalent cation aCSF (McLean et al., 1996). Spontaneous EPSCs were $>80$ times more frequent. Therefore, EPSC values obtained from measurement windows were adjusted by subtracting expected spontaneous events based on the frequency and amplitude of spontaneous EPSCs recorded for each cell before photostimulation. To further evaluate the effects of spontaneous EPSCs on evoked responses, we analyzed $20 \mathrm{~ms}$ epochs preceding each photostimulus (supplemental Fig. 2, available at www.jneurosci.org as supplemental material). Maps based on spontaneous EPSCs displayed few, if any, sites with composite amplitudes $>25$ pA. In contrast, maps of evoked EPSCs included multiple sites with composite amplitudes $>25 \mathrm{pA}$ in both control and epileptic rats. These findings indicate most larger events that occurred during measurement windows were evoked by photostimulation.

Neuronal-specific nuclear protein-biocytin immunohistochemistry. To visualize biocytin-labeled neurons after recording, slices were fixed in $4 \%$ paraformaldehyde in $0.1 \mathrm{M}$ phosphate buffer $(\mathrm{PB})$ at $4^{\circ} \mathrm{C}$ for at least $24 \mathrm{~h}$. After fixation, slices were stored in 30\% ethylene glycol and $25 \%$ glycerol in $50 \mathrm{~mm} \mathrm{~PB}$ at $-20^{\circ} \mathrm{C}$ before being processed using a whole-mount protocol with counterstaining by neuronal-specific nuclear protein $(\mathrm{NeuN})$ immunoreactivity. Slices were rinsed in $0.5 \%$ Triton X-100 and $0.1 \mathrm{~m}$ glycine in $0.1 \mathrm{M} \mathrm{PB}$ and then placed in a blocking solution containing $0.5 \%$ Triton X-100, $2 \%$ goat serum (Vector Laboratories, Burlingame, CA), and $2 \%$ bovine serum albumin in $0.1 \mathrm{~m} \mathrm{~PB}$ for $4 \mathrm{~h}$. Slices were incubated in mouse anti-NeuN serum (1:1000; MAB377; Chemicon, Temecula, CA) in blocking solution overnight. After a rinsing step, slices were incubated with Alexa 594 streptavidin $(5 \mu \mathrm{g} / \mathrm{ml})$ and Alexa 488 goat anti-mouse $(10 \mu \mathrm{g} / \mathrm{ml}$; Invitrogen, Eugene, OR) in blocking solution overnight. Slices were rinsed, mounted on slides, and coverslipped with Vectashield (Vector Laboratories) before being examined with a confocal microscope (LSM 5 Pascal; Zeiss). Layer II stellate cells were morpholog- ically identified by their soma position in layer II, stellate pattern of dendritic projections, and spiny dendrites (Buckmaster et al., 2004).

All statistical values are presented as mean \pm SEM. Statistical differences were measured using unpaired Student's $t$ test or ANOVA.

\section{Results}

\section{Layer II stellate cell responses to focal glutamate photo-uncaging}

Laser-scanning photo-uncaging of glutamate in layer II medial entorhinal cortex evoked direct, synaptic, and mixed responses in stellate cells (Fig. 1B,C). Direct responses are generated when uncaged glutamate binds receptors on recorded cells, and synaptic responses are generated when uncaged glutamate evokes at least one action potential in a neuron that synapses with recorded cells (Callaway and Katz, 1993). Latencies of direct responses recorded in voltage-clamp mode were short, $<10 \mathrm{~ms}$, and their amplitudes reached $500 \mathrm{pA}$. Synaptic responses occurred at longer latencies, and their individual amplitudes were 5-56 and 26-274 pA for EPSCs and IPSCs, respectively.

\section{Similar direct responses of entorhinal cortical neurons to photostimulation in control and epileptic animals}

Current-clamp recording was used to evaluate responses of layer II stellate cells in slices from control and epileptic rats $(n=10$ and 8 cells, respectively) (Fig. $2 A-C$ ). These experiments used grids of photostimulation sites $400 \mu \mathrm{m}$ along the mediolateral axis and $350 \mu \mathrm{m}$ along the pial-white matter axis at $50 \mu \mathrm{m}$ center-tocenter spacing with recorded cells near grid center. Photostimulation evoked depolarizations that sometimes triggered one and rarely more action potentials. Photostimulation sites that evoked action potentials ("hotspots") tended to be near recorded somata. Average maps of action potential-evoking stimulation sites were similar in control and epileptic rats (Fig. 2 B). Control and epileptic animals displayed similar average numbers of action potentials evoked per photostimulation map, hotspots per map, and action potentials per hotspot (Fig. 2C). Furthermore, mean distances of hotspots from recorded somata were similar in control and epileptic animals (Fig. 2C). These findings indicate that photostimulation of layer II stellate cells in medial entorhinal cortex evoked similar direct responses in control and epileptic animals. Therefore, any observed differences between control and epileptic rats in excitatory synaptic responses are unlikely to be attributable to differences in responsiveness of photostimulated presynaptic neurons.

To evaluate recurrent circuits in layer II, photostimulation was confined to that layer. Apical dendrites of neurons in deeper layers, however, extend through layer II. We tested whether photostimulation of apical dendrites in layer II evokes action potentials in layer III pyramidal cells in slices from control and epileptic rats $(n=8$ cells in each group) (Fig. $2 D)$. These experiments used grids of photostimulation sites up to $500 \mu \mathrm{m}$ along the mediolateral axis and $500 \mu \mathrm{m}$ along the pial-white matter axis at $50 \mu \mathrm{m}$ center-to-center spacing with recorded layer III pyramidal cells near grid center. The overlying layer II was stimulated in a grid pattern up to $1100 \mu \mathrm{m}$ along the mediolateral axis and up to 500 $\mu \mathrm{m}$ along the pial-white matter axis at $50 \mu \mathrm{m}$ center-to-center spacing. Photostimulation close to recorded somata in layer III evoked action potentials in all cells. In contrast, photostimulation in layer II overlying the same recorded layer III pyramidal cells never evoked action potentials. These findings suggest that synaptic responses evoked by photostimulation in layer II are not caused by activation of neurons in deeper layers. 
A

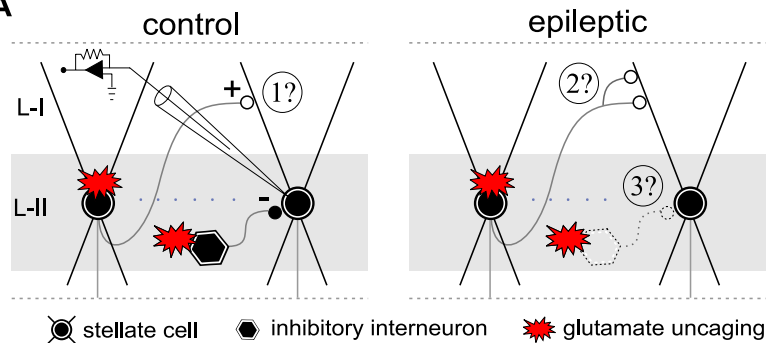

B1

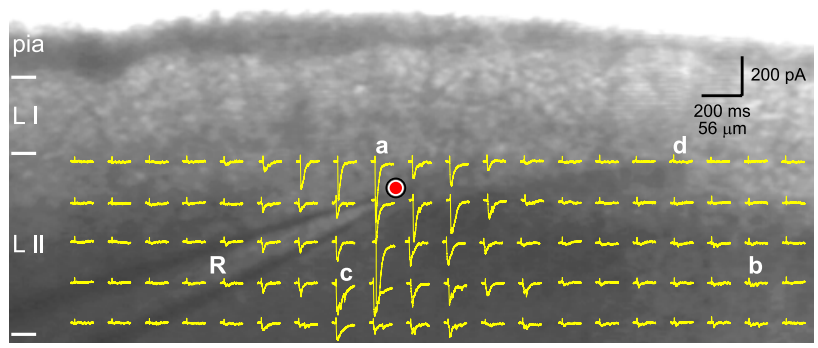

B2

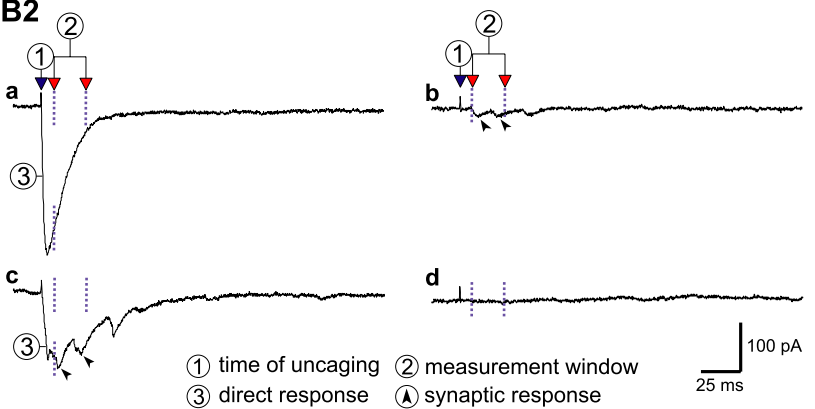

C
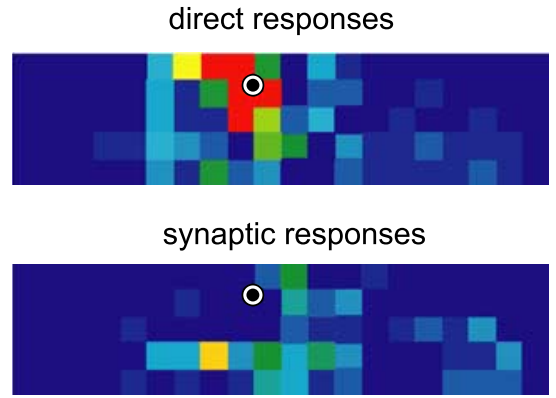

Figure 1. Laser-scanning photostimulation in layer II of medial entorhinal cortex in brain slices from control and epileptic rats uncages glutamate and evokes direct and synaptic responses. A, Questions addressed in this study: (1) do layer II stellate cells form recurrent excitatory synapses in control tissue? (2) do these neurons sprout axon collaterals and develop novel recurrent excitatory synapses in epileptic animals? and (3) is recurrent inhibitory synaptic input onto stellate cells from GABAergic interneurons in layer II diminished in epileptic animals? Laser-scanning photostimulation in layer II (L-II; gray area) activated stellate cells and inhibitory interneurons while responses were recorded in stellate cells. In this study, the term "recurrent inhibition" does not specify whether the activated interneurons receive synaptic input from the stellate cells in which IPSCs are recorded. B1, Overlay of typical responses recorded in a stellate cell evoked by pseudorandom and systematic uncaging of glutamate by flash photolysis in layer II (L II). In this and subsequent figures, recorded soma position is indicated by $\bigcirc$. The recorded neuron in layer II medial entorhinal cortex was visualized using a microscope equipped with infrared optics ( $R$, recording electrode). $B 2$, Enlargement of some traces from $B 1$ reveals four types of photostimulation-evoked responses: $a$, direct; b, synaptic; c, mixed; d, no response. Direct responses recorded in voltage-clamp mode (holding voltage, $-70 \mathrm{mV}$ ) peaked within $10 \mathrm{~ms}$ of photostimulation. Events that peaked during a measurement window $10-30$ $\mathrm{ms}$ after photostimulation (between blue dotted lines) were identified as potential excitatory synaptic responses. C, Glutamate photo-uncaging maps of direct (top) and synaptic (bottom) responses of cell shown in $\boldsymbol{B}$. Direct responses are expressed as peak amplitudes occurring within $10 \mathrm{~ms}$ of photostimulation. Synaptic responses are expressed as composite EPSC amplitudes occurring $10-30 \mathrm{~ms}$ after photostimulation.
A

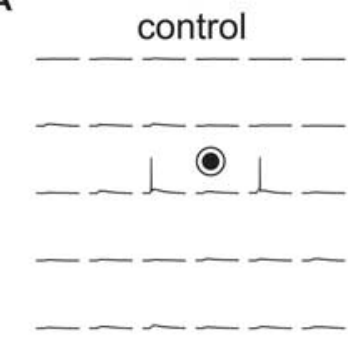

B
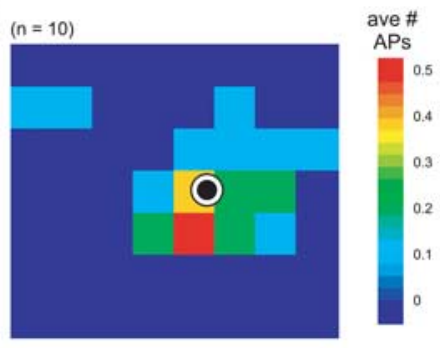

C
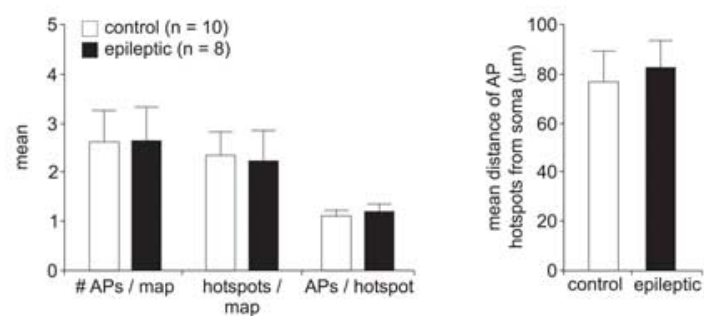

D

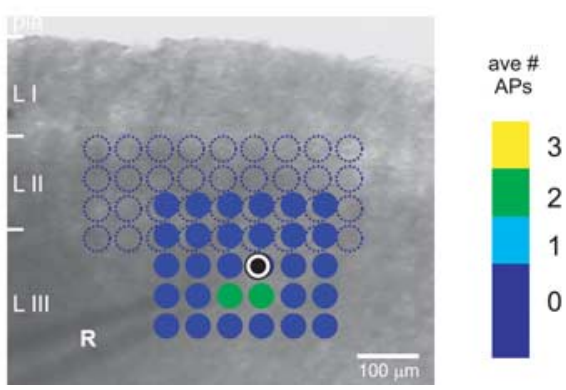

Figure 2. Direct responses recorded in current-clamp mode of entorhinal cortical neurons to glutamate photo-uncaging are similar in control and epileptic animals. $\boldsymbol{A}$, Responses of layer II stellate cells in control and epileptic animals to photostimulation. $\boldsymbol{B}$, Color-coded maps depict average number of action potentials evoked at each stimulation site in 10 cells from control and eight cells from epileptic animals (left and right panels, respectively). C, Quantitative comparison of action potential maps from control and epileptic animals. Hotspots are stimulation sites that evoke an action potential. $\boldsymbol{D}$, Control experiment to evaluate specificity of layer II photostimulation. Current-clamp recordings were obtained from a layer III pyramidal cell (๑). Photostimulation maps indicate number of action potentials evoked. Stimulation near the recorded soma in layer III (L III) evoked action potentials, whereas stimulation in overlying layer II (LII) did not. Overlapping stimulation maps are indicated by filled and open dotted circles. r, Recording electrode.

\section{Similar recurrent excitatory circuits in layer II of control and} epileptic animals

To evaluate recurrent excitatory circuits, stellate cells were voltage clamped at $-70 \mathrm{mV}$, and layer II was randomly and systematically photostimulated in a grid pattern up to $1200 \mu \mathrm{m}$ along the mediolateral axis and $200-250 \mu \mathrm{m}$ along the pial-white matter axis at $50 \mu \mathrm{m}$ center-to-center spacing with recorded stellate cells near grid center (Fig. $3 A$ ). In slices from control rats, synaptic responses were evoked in $19 \pm 2 \%$ of photostimulation sites in 
A control epileptic

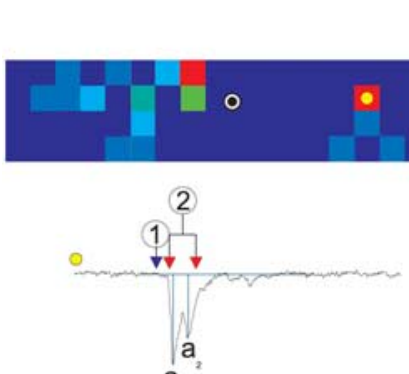

EPSCs

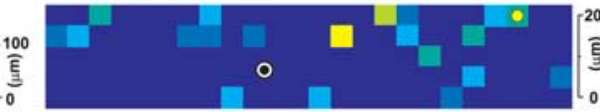

a

\begin{abstract}
- cell soma (recording site)
trace location on map
\end{abstract}

B
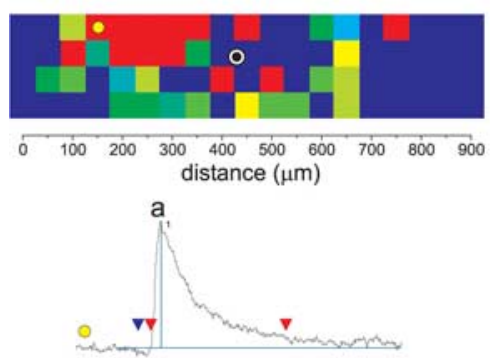

C
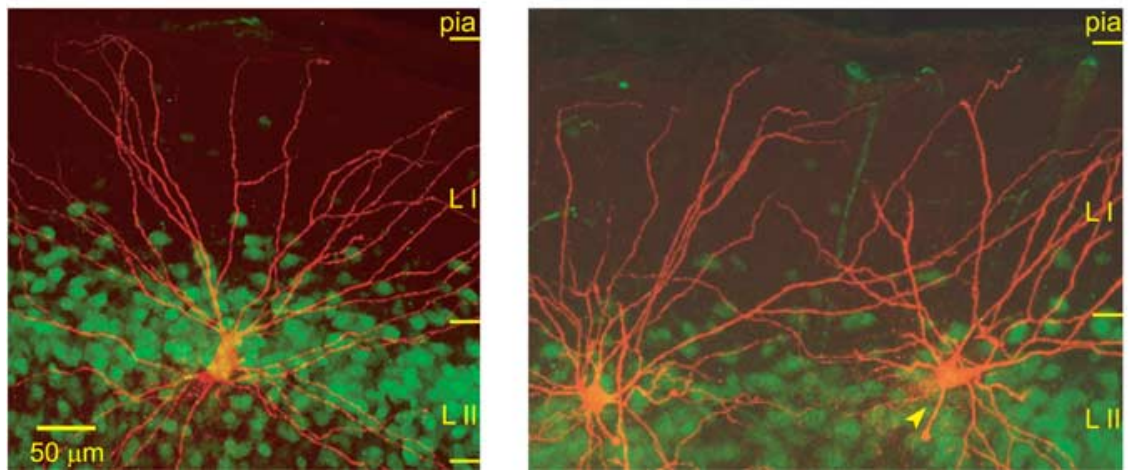

Figure 3. Recurrent circuits in layer Il of medial entorhinal cortex in control and epileptic animals evaluated with laser-scanning photostimulation. $\boldsymbol{A}$, Maps depict composite amplitudes of EPSCs (holding potential, $-70 \mathrm{mV}$ ) occurring in measurement windows $10-30$ ms after photostimulation. Traces under maps are typical responses, and corresponding photostimulation sites are indicated by filled yellow circles. $\boldsymbol{B}$, Maps from the same cells showing composite amplitudes of IPSCs (holding potential, $0 \mathrm{mV}$ ) occurring in measurement windows $10-110$ ms after photostimulation. Traces under maps are typical responses. $C$, Neurons from which data in $\boldsymbol{A}$ and $\boldsymbol{B}$ were obtained (red, biocytin; green, NeuN immunoreactivity; L I-II, layers I-II). The yellow arrowhead indicates a cell from epileptic rat whose responses are shown above.

layer II, suggesting that stellate cells in medial entorhinal cortex are interconnected within a recurrent excitatory network. Percentages of photostimulation sites that evoked synaptic responses were plotted with respect to mediolateral distance from recorded stellate cells (Fig. 4A). Within a span of $\sim 900 \mu \mathrm{m}$, proportions of responding sites remained relatively constant and then decremented at greater distances. Average individual EPSC amplitude at responding sites was $15 \pm 1 \mathrm{pA}$. Average composite EPSC amplitudes tended to peak at photostimulation sites near recorded somata and declined with mediolateral distance (Fig. 4C).

The same photostimulation protocol was used to evaluate recurrent excitatory circuits of stellate cells in epileptic rats. Average number of photostimulation sites tested per stellate cell and percentage of responding sites were similar to controls (Table 1). The percentage of responding sites along the mediolateral extent of layer II was not significantly different from controls ( $p=0.17$; ANOVA) (Fig. $4 A$ ). The average amplitude of individual evoked EPSCs was similar to that of controls (Table 1). The mediolateral extent of average composite EPSC amplitude was similar to controls $(p>0.5$; ANOVA) (Fig. 4C). Together, these findings reveal similar recurrent excitatory circuits among layer II stellate cells in control and epileptic rats.

\section{Reduced recurrent inhibitory circuits in epileptic animals}

In a subset of stellate cells used to obtain EPSC data, the same photostimulation protocol was used to evaluate recurrent inhibitory circuits in layer II, except recordings were obtained at a holding potential of $0 \mathrm{mV}$ to minimize EPSCs and enhance detectability of IPSCs (Fig. 3B). In control rats, IPSCs were evoked in $14 \pm$ $4 \%$ of tested sites. The percentage of IPSCresponding sites was greatest near recorded somata and declined relatively symmetrically along the mediolateral axis (Fig. $4 B$ ). The mean amplitude of individual evoked IPSCs at responding sites was $98 \pm 14 \mathrm{pA}$, and average composite IPSC amplitude was largest at photostimulation sites near recorded somata and declined relatively symmetrically with mediolateral distance (Fig. $4 D$ ).

In epileptic rats, photostimulation maps revealed far fewer IPSC-evoking sites (Fig. 3B). IPSCs were evoked in $2 \pm$ $1 \%$ of tested sites, which was only $17 \%$ of controls $(p<0.005 ; t$ test). The plot of percentage of responding sites along the mediolateral axis was relatively flat and less than control values $(p<0.005$; ANOVA) (Fig. 4B). Mean individual IPSC amplitude was $63 \%$ of controls, but the difference was not significant $(p=0.1 ; t$ test) (Table 1). Average composite IPSC amplitude in epileptic rats was relatively flat along the mediolateral axis and less than control values ( $p<0.0005$; ANOVA).

\section{Discussion}

This study used laser-scanning photostimulation to evaluate recurrent circuits in layer II of medial entorhinal cortex in slices from control and epileptic pilocarpine-treated rats. The principal findings provide evidence for recurrent excitation among stellate cells in controls, similar levels of recurrent excitation among stellate cells in control and epileptic rats, and reduced recurrent inhibition of stellate cells in epileptic animals.

\section{Recurrent excitation among layer II stellate cells in medial entorhinal cortex}

Principal cells in layer II medial entorhinal cortex project primary axons to the middle molecular layer of the dentate gyrus (Steward, 1976). Within the entorhinal cortex, primary axons give rise 

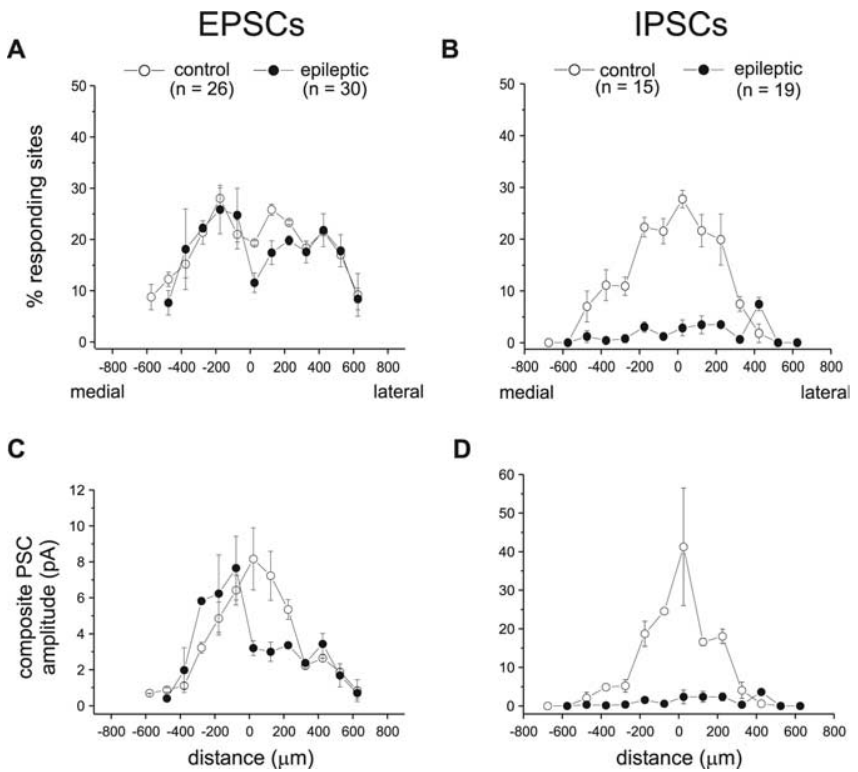

D

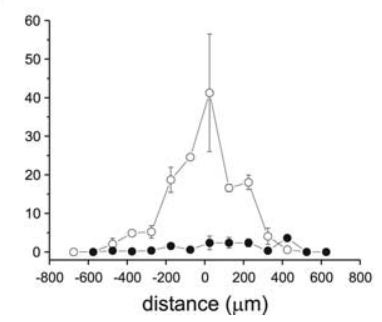

Figure 4. Mediolateral distributions of probabilities of evoking a response $(\boldsymbol{A}, \boldsymbol{B})$ and average composite PSC amplitudes $(\boldsymbol{C}, \boldsymbol{D})$ in control and epileptic groups (soma at $0 \mu \mathrm{m}$ ) for EPSCS (left column) and IPSCS (right column). Error bars, where larger than the size of the symbols, indicate SEM.

to collaterals that extend long distances, spanning $>1 \mathrm{~mm}$, in layers I and II where stellate cell dendrites are located (Lingenhöhl and Finch, 1991; Buckmaster et al., 2004). The arborization of their axon collaterals suggests stellate cells might normally form an associative network. However, recurrent excitatory synapses between layer II neurons were undetectable by dual intracellular recording (Dhillon and Jones, 2000). Although paired recordings are the most direct approach for evaluating monosynaptic connectivity, they are laborious, which limits numbers of possible connections that can be tested. Sensitive, whole-cell, voltage-clamp recording with photostimulation is efficient and has been used successfully to detect and evaluate recurrent excitatory circuits in other brain regions (Molnár and Nadler, 1999; Sawatari and Callaway, 2000; Shao and Dudek, 2004; Jin et al., 2006). Using this approach, we found synaptic events generated by photostimulation sites in layer II of medial entorhinal cortex $>500 \mu \mathrm{m}$ from recorded stellate cells.

Control experiments were performed to evaluate direct responses of entorhinal neurons to photostimulation. Although layer II stellate cells are hyperexcitable in rat models of temporal lobe epilepsy, the hyperexcitability does not appear to be attributable to changes in intrinsic electrophysiological properties (Bear et al., 1996; Kobayashi et al., 2003). Results of the present study are consistent with these previous results, because direct responses of layer II stellate cells were similar in control and epileptic rats. Neurons in deeper layers of entorhinal cortex, however, display epilepsy-related enhancement of persistent sodium currents (Agrawal et al., 2003) and reduction of h-current (Shah et al., 2004), which might make them more responsive to glutamate uncaging in the vicinity of their apical dendrites in layer II. Therefore, we compared responses of layer III neurons to photostimulation in overlying layer II of control and epileptic rats. Layer II photostimulation was not observed to evoke action potentials in deeper neurons, and this was unlikely to be a confounding variable in our experiments. Thus, layer II photostimulation data are consistent with previous anatomical evidence and suggest that stellate cells are interconnected by an associative net- work, which might contribute to memory function of hippocampal formation (Marr, 1971; Hafting et al., 2005).

EPSC responses to layer II photostimulation were measured with several parameters, and results of control and epileptic groups were similar. No significant differences were found in mean individual EPSC amplitude, percentage of responding sites, or average composite EPSC amplitude. Both groups displayed responding sites across a span of $\sim 1 \mathrm{~mm}$ along the mediolateral axis. Average composite EPSC amplitude peaked close to recorded somata and decreased with mediolateral distance. These findings suggest that within $\pm 500 \mu \mathrm{m}$ mediolaterally, layer II stellate cells are interconnected, and closer cells make stronger synaptic connections than cells farther away. It is unclear whether this might be a consequence of axon amputation during slice preparation or a native feature of the circuit.

\section{Reduced recurrent inhibition of layer II stellate cells in epileptic animals}

A subset of stellate cells from which photostimulus-evoked EPSCs were obtained were also used to evaluate IPSCs. In controls, relatively large amplitude IPSCs were evoked by layer II stimulation. Over half of the GABAergic interneurons in layer II of medial entorhinal cortex are parvalbumin immunoreactive (Miettinen et al., 1996), and basket cells in layer II make a dense axon plexus that spans up to $1 \mathrm{~mm}$ mediolaterally (Tamamaki and Nojyo, 1993). We found similar mediolateral extents of percentage of IPSC-responding sites and average composite IPSC amplitudes in control animals. These findings are consistent with previous reports that layer II stellate cells normally receive strong inhibitory synaptic input (Woodhall et al., 2005).

In animal models of temporal lobe epilepsy, layer II stellate cells generate excessive, spontaneous, hypersynchronous, excitatory synaptic input to the dentate gyrus (Buckmaster and Dudek, 1997; Scharfman et al., 1998; Kobayashi et al., 2003). As discussed above, underlying mechanisms do not appear to involve changes in stellate cell intrinsic electrophysiology or extent of recurrent excitatory synaptic connectivity. Instead, reduced inhibition of layer II stellate cells has been proposed by two different mechanisms. One mechanism is the dormant interneuron hypothesis (Du et al., 1995; Bear et al., 1996; Eid et al. 1999; Schwarcz et al., 2000). It contends that layer III pyramidal cells provide a major source of excitatory synaptic input to layer III GABAergic interneurons. The hypothesis proposes that after an epileptogenic injury, layer III GABAergic interneurons survive and maintain inhibitory synapses with their targets, including layer II stellate cells, but become "dormant" or inactive, because their major excitatory afferents (layer III pyramidal cells) are lost. If GABAergic interneurons survive and maintain inhibitory synapses with layer II stellate cells, as the hypothesis predicts, one would expect direct activation of interneurons by glutamate uncaging to generate similar IPSC maps in control and epileptic animals. However, that was not the case.

Alternatively, layer II stellate cell hyperexcitability has been attributed to loss of GABAergic interneurons and reduced inhibitory synaptic input (Kumar and Buckmaster, 2006). In this scenario, one would expect photostimulation to evoke IPSCs in stellate cells less frequently in epileptic animals, because there were fewer interneurons to stimulate. Our findings are consistent with this hypothesis. We found that fewer photostimulation sites evoked IPSCs in stellate cells and average composite IPSC amplitudes were reduced in epileptic rats. These epilepsy-related changes could be attributable to differences in direct responses of interneurons to photostimulation. However, glutamate 
receptor-mediated events are not reduced in entorhinal interneurons of epileptic rats in terms of frequency and amplitude of spontaneous EPSCs (Kumar and Buckmaster, 2006), suggesting epilepsy-related differences in responsiveness of interneurons to glutamate uncaging are unlikely. Postsynaptic differences of stellate cells in response to $\mathrm{GABA}_{\mathrm{A}}$ receptor-mediated input is an unlikely explanation, because miniature IPSC amplitudes are normal in layer II stellate cells after epileptogenic treatments (Kobayashi et al., 2003; Kumar and Buckmaster, 2006). Other possibilities include epilepsy-related changes in connectivity between interneurons and stellate cells and differential survival of interneuron subtypes. In addition, presynaptic receptors modulate release of GABA in entorhinal cortex in control rats (Woodhall et al., 2001; Bailey et al., 2004), and epilepsy-related changes in presynaptic receptors at GABAergic terminals could differentially affect probabilities of synaptic release. Regardless of whether and how individual IPSC responses and presynaptic release probabilities are different in epileptic versus control rats, reduction of IPSC-evoking sites suggests reduced inhibitory control contributes to hyperexcitability of layer II stellate cells in medial entorhinal cortex.

In conclusion, photostimulation of layer II medial entorhinal cortex revealed excitatory, associative interconnections that could contribute to mnemonic mechanisms and were similar in control and epileptic rats. Recurrent inhibitory responses, in contrast, were substantially diminished in epileptic animals and might contribute to seizure-genesis in this model of temporal lobe epilepsy.

\section{References}

Agrawal N, Alonso A, Ragsdale DS (2003) Increased persistent sodium currents in rat entorhinal cortex layer $\mathrm{V}$ neurons in a post-status epilepticus model of temporal lobe epilepsy. Epilepsia 44:1601-1604.

Ang CW, Carlson GC, Coulter DA (2006) Massive and specific dysregulation of direct cortical input to the hippocampus in temporal lobe epilepsy. J Neurosci 26:11850-11856.

Angulo MC, Kozlov AS, Charpak S, Audinat E (2004) Glutamate released from glial cells synchronizes neuronal activity in the hippocampus. J Neurosci 24:6920-6927.

Bailey SJ, Dhillon A, Woodhall GL, Jones RSG (2004) Lamina-specific differences in $\mathrm{GABA}_{\mathrm{B}}$ autoreceptor-mediated regulation of spontaneous GABA release in rat entorhinal cortex. Neuropharmacology 46:31-42.

Bartolomei F, Khalil M, Wendling F, Sontheimer A, Régis J, Ranjeva J-P, Guye M, Chauvel P (2005) Entorhinal cortex involvement in human mesial temporal lobe epilepsy: an electrophysiologic and volumetric study. Epilepsia 46:677-687.

Bear J, Fountain NB, Lothman EW (1996) Responses of the superficial entorhinal cortex in vitro in slices from naïve and chronically epileptic rats. J Neurophysiol 76:2928-2940.

Bernasconi N, Bernasconi A, Andermann F, Dubeau F, Feindel W, Reutens DC (1999) Entorhinal cortex in temporal lobe epilepsy. A quantitative MRI study. Neurology 52:1870-1876.

Biella G, Uva L, Hofmann UG, de Curtis M (2002) Associative interactions within the superficial layers of the entorhinal cortex of the guinea pig. J Neurophysiol 88:1159-1165.

Buckmaster PS (2004) Laboratory animal models of temporal lobe epilepsy. Comp Med 54:473-485.

Buckmaster PS, Dudek FE (1997) Network properties of the dentate gyrus in epileptic rats with hilar neuron loss and granule cell axon reorganization. J Neurophysiol 77:2685-2696.

Buckmaster PS, Alonso A, Canfield DR, Amaral DG (2004) Dendritic morphology, local circuitry, and intrinsic electrophysiology of principal neurons in the entorhinal cortex of macaque monkeys. J Comp Neurol 470:314-329.

Callaway EM, Katz LC (1993) Photostimulation using caged glutamate reveals functional circuitry in living brain slices. Proc Natl Acad Sci USA 90:7661-7665.

Clifford DB, Olney JW, Maniotis A, Collins RC, Zorumski CF (1987) The functional anatomy and pathology of lithium-pilocarpine and high-dose pilocarpine seizures. Neuroscience 23:953-968.

Dawodu S, Thom M (2005) Quantitative neuropathology of the entorhinal cortex region in patients with hippocampal sclerosis and temporal lobe epilepsy. Epilepsia 46:23-30.

Deleuze C, Huguenard JR (2006) Distinct electrical and chemical connectivity maps in the thalamic reticular nucleus: potential roles in synchronization and sensation. J Neurosci 26:8633-8645.

Dhillon A, Jones RSG (2000) Laminar differences in recurrent excitatory transmission in the rat entorhinal cortex in vitro. Neuroscience 99:413-422.

Du F, Whetsell Jr WO, Abou-Khalil B, Blumenkopf B, Lothman EW, Schwarcz R (1993) Preferential neuronal loss in layer III of the entorhinal cortex in patients with temporal lobe epilepsy. Epilepsy Res 16:223-233.

Du F, Eid T, Lothman EW, Köhler C, Schwarcz R (1995) Preferential neuronal loss in layer III of the medial entorhinal cortex in rat models of temporal lobe epilepsy. J Neurosci 15:6301-6313.

Eid T, Schwarcz R, Ottersen OP (1999) Ultrastructure and immunocytochemical distribution of GABA in layer III of the rat medial entorhinal cortex following aminooxyacetic acid-induced seizures. Exp Brain Res 125:463-475.

Engel Jr J, Williamson PD, Wieser H-G (1997) Mesial temporal lobe epilepsy. In: Epilepsy: a comprehensive textbook (Engel Jr J, Pedley TA, eds), pp 2417-2426. Philadelphia: Lippincott-Raven.

Fellin T, Pascual O, Gobbo S, Pozzan T, Haydon PG, Carmignoto G (2004) Neuronal synchrony mediated by astrocytic glutamate through activation of extrasynaptic NMDA receptors. Neuron 43:729-743.

Germroth P, Schwerdtfeger WK, Buhl EH (1991) Ultrastructure and aspects of functional organization of pyramidal and nonpyramidal entorhinal projection neurons contributing to the perforant path. J Comp Neurol 305:215-231.

Hafting T, Fyhn M, Molden S, Moser M-B, Moser EI (2005) Microstructure of a spatial map in the entorhinal cortex. Nature 436:801-806.

Jin X, Prince DA, Huguenard JR (2006) Enhanced excitatory synaptic connectivity in layer $\mathrm{V}$ pyramidal neurons of chronically injured epileptogenic neocortex in rats. J Neurosci 26:4891-4900.

Jutila L, Ylinen A, Partanen K, Alafuzoff I, Mervaala E, Partanen J, Vapalahti M, Vainio P, Pitkänen A (2001) MR volumetry of the entorhinal, perirhinal, and temporopolar cortices in drug-refractory temporal lobe epilepsy. Am J Neuroradiol 22:1490-1501.

Kobayashi M, Wen X, Buckmaster PS (2003) Reduced inhibition and increased output of layer II neurons in the medial entorhinal cortex in a model of temporal lobe epilepsy. J Neurosci 23:8471-8479.

Köhler C (1986) Intrinsic connections of the rat retrohippocampal region in the rat brain. II. The medial entorhinal area. J Comp Neurol 246:149-169.

Kumar SS, Buckmaster PS (2006) Hyperexcitability, interneurons, and loss of GABAergic synapses in entorhinal cortex in a model of temporal lobe epilepsy. J Neurosci 26:4613-4623.

Lenz RA, Alger BE (1999) Calcium dependence of depolarization-induced suppression of inhibition in rat hippocampal CA1 pyramidal neurons. J Physiol (Lond) 521:147-157.

Lingenhöhl K, Finch DM (1991) Morphological characterization of rat entorhinal neurons in vivo: soma-dendritic structure and axonal domains. Exp Brain Res 84:57-74.

Lynch M, Sutula T (2000) Recurrent excitatory connectivity in the dentate gyrus of kindled and kainic acid-treated rats. J Neurophysiol 83:693-704.

Marr D (1971) Simple memory: a theory for archicortex. Proc R Soc Lond B Biol Sci 262:23-81.

McKinney RA, Debanne D, Gähwiler BH, Thompson SM (1997) Lesioninduced axonal sprouting and hyperexcitability in the hippocampus in vitro: implications for the genesis of posttraumatic epilepsy. Nat Med 3:990-996.

McLean HA, Caillard O, Khazipov R, Ben-Ari Y, Gaiarsa J-L (1996) Spontaneous release of GABA activates $\mathrm{GABA}_{\mathrm{B}}$ receptors and controls network activity in the neonatal rat hippocampus. J Neurophysiol 76:1036-1046.

Miettinen M, Koivisto E, Riekkinen P, Miettinen R (1996) Coexistence of parvalbumin and GABA in nonpyramidal neurons of the rat entorhinal cortex. Brain Res 706:113-122.

Molnár P, Nadler JV (1999) Mossy fiber-granule cell synapses in the normal and epileptic rat dentate gyrus studied with minimal laser photostimulation. J Neurophysiol 82:1883-1894. 
Nadler JV, Perry BW, Cotman CW (1980) Selective reinnervation of hippocampal area CA1 and the fascia dentata after destruction of CA3-CA4 afferents with kainic acid. Brain Res 182:1-9.

Perez Y, Morin F, Beaulieu C, Lacaille J-C (1996) Axonal sprouting of CA1 pyramidal cells in hyperexcitable hippocampal slices of kainate-treated rats. Eur J Neurosci 8:736-748.

Prince DA, Tseng GF (1993) Epileptogenesis in chronically injured cortex: in vitro studies. J Neurophysiol 69:1276-1291.

Ribak CE, Seress L, Weber P, Epstein CM, Henry TR, Bakay RAE (1998) Alumina gel injections into the temporal lobe of Rhesus monkeys cause complex partial seizures and morphological changes found in human temporal lobe epilepsy. J Comp Neurol 401:266-290.

Rutecki PA, Grossman RG, Armstrong D, Irish-Loewen S (1989) Electrophysiological connections between the hippocampus and entorhinal cortex in patients with complex partial seizures. J Neurosurg 70:667-675.

Salin P, Tseng G-F, Hoffman S, Parada I, Prince DA (1995) Axonal sprouting in layer $\mathrm{V}$ pyramidal neurons of chronically injured cerebral cortex. J Neurosci 15:8234-8245.

Sawatari A, Callaway EM (2000) Diversity and cell type specificity of local excitatory connections to neurons in layer $3 \mathrm{~B}$ of monkey primary visual cortex. Neuron 25:459-471.

Scharfman HE, Goodman JH, Du F, Schwarcz R (1998) Chronic changes in synaptic responses of entorhinal and hippocampal neurons after aminooxyacetic acid (AOAA)-induced entorhinal cortical neuron loss. J Neurophysiol 80:3031-3046.

Schwarcz R, Eid T, Du F (2000) Neurons in layer III of the entorhinal cortex. A role in epileptogenesis and epilepsy? Ann NY Acad Sci 911:328-342.

Schwob JE, Fuller T, Price JL, Olney JW (1980) Widespread patterns of neuronal damage following systemic or intracerebral injections of kainic acid: a histological study. Neuroscience 5:991-1014.

Segal M, Landis S (1974) Afferents to the hippocampus of the rat studied with the method of retrograde transport of horseradish peroxidase. Brain Res 78:1-15.

Shah MM, Anderson AE, Leung V, Lin X, Johnston D (2004) Seizureinduced plasticity of $\mathrm{h}$ channels in entorhinal cortical layer III pyramidal neurons. Neuron 44:495-508.
Shao L-R, Dudek FE (2004) Increased excitatory synaptic activity and local connectivity of hippocampal CA1 pyramidal cells in rats with kainateinduced epilepsy. J Neurophysiol 92:1366-1373.

Shepherd GMG, Pologruto TA, Svoboda K (2003) Circuit analysis of experience-dependent plasticity in the developing rat barrel cortex. Neuron 38:277-289.

Spencer SS, Spencer DD (1994) Entorhinal-hippocampal interactions in medial temporal lobe epilepsy. Epilepsia 35:721-727.

Steward O (1976) Topographic organization of the projections from the entorhinal area to the hippocampal formation of the rat. J Comp Neurol 167:285-314.

Steward O, Scoville SA (1976) Cells of origin of entorhinal cortical afferents to the hippocampus and fascia dentata of the rat. J Comp Neurol 169:347-370

Tamamaki N, Nojyo Y (1993) Projection of the entorhinal layer II neurons in the rat as revealed by intracellular pressure-injection of neurobiotin. Hippocampus 3:471-480.

Tolner EA, Kloosterman F, van Vliet EA, Witter MP, Lopes da Silva FH, Gorter JA (2005) Presubiculum stimulation in vivo evokes distinct oscillations in superficial and deep entorhinal cortex layers in chronic epileptic rats. J Neurosci 25:8755-8765.

Wilson CL, Isokawa M, Babb TL, Crandall PH (1990) Functional connections in the human temporal lobe. Exp Brain Res 82:279-292.

Woodhall GL, Evans IP, Jones RSG (2001) Activation of presynaptic group III metabotropic glutamate receptors depresses spontaneous inhibition in layer V of the rat entorhinal cortex. Neuroscience 105:71-78.

Woodhall GL, Bailey SJ, Thompson SE, Evans IP, Jones RSG (2005) Fundamental differences in spontaneous synaptic inhibition between deep and superficial layers of the rat entorhinal cortex. Hippocampus 15:232-245.

Wozny C, Gabriel S, Jandova K, Schulze K, Heinemann U, Behr J (2005) Entorhinal cortex entrains epileptiform activity in CA1 in pilocarpinetreated rats. Neurobiol Dis 19:451-460.

Yilmazer-Hanke DM, Wolf HK, Schramm J, Elger CE, Wiestler OD, Blumcke I (2000) Subregional pathology of the amygdala complex and entorhinal region in surgical specimens from patients with pharmacoresistant temporal lobe epilepsy. J Neuropathol Exp Neurol 59:907-920. 